\begin{tabular}{|c|c|}
\hline Title & Effects of vacuum environment on small fatigue crack propagation in Ti-6A I-4V \\
\hline Author(s) & Yoshinaka, Fumiyoshi; Nakamura, Takashi; Takaku, Kazuaki \\
\hline Citation & $\begin{array}{l}\text { International journal of fatigue, 91, 29-38 } \\
\text { https://doi.org/10.1016/.ijfatigue.2016.05.024 }\end{array}$ \\
\hline Issue Date & $2016-10$ \\
\hline DOC URL & http:/hdl.handle.net/2115//1584 \\
\hline Rights & $\begin{array}{l}\text { (0) 2016. This manuscript version is made available under the CC-BY-NC-ND } 4.0 \text { license } \\
\text { http://creativecommons.org/icenses/by-nc-nd/4.0/ }\end{array}$ \\
\hline Rights(URL) & http://creativecommons.org/icenses/by-nc-nd/4.0/ \\
\hline Type & article (author version) \\
\hline File Information & Effects of vacuum environment on small fatigue crack propagation in Ti-6A I- $4 \mathrm{~V}$.pdf \\
\hline
\end{tabular}

Instructions for use 


\title{
Effects of vacuum environment on small fatigue crack propagation in Ti-6Al-4V
}

\author{
Fumiyoshi Yoshinaka a, b, Takashi Nakamura, and Kazuaki Takaku ${ }^{\mathrm{a}}$ \\ ${ }^{a}$ Division of Mechanical and Space Engineering, Graduate School of Engineering, Hokkaido University
}

Kita 13, Nishi 8, Kita-ku, Sapporo, Hokkaido 060-8628, Japan

b JSPS Research Fellow, Japan

${ }^{\mathrm{c}}$ Division of Mechanical and Space Engineering, Faculty of Engineering, Hokkaido University

Kita 13, Nishi 8, Kita-ku, Sapporo, Hokkaido 060-8628, Japan

Tel.: +81 117066421

E-mail: yoshinaka@eis.hokudai.ac.jp

\begin{abstract}
Small fatigue crack propagation tests were conducted on Ti-6Al-4V in ultrahigh vacuum, air, and argon to clarify the effects of vacuum on crack propagation processes. The crack propagation rate in vacuum was significantly lower than that in air. The crack propagation rate in argon agreed with that in air in the small crack regime; however, it became similar to that in vacuum in the long crack regime. This indicates that the existence of gases has significant effects in the small crack regime, even if they are chemically inert. These results led us to conclude that, in addition to chemical inactivity, the absence of physical adsorption plays an important role in the retarding effect of vacuum on small crack propagation.
\end{abstract}

Keywords: Small fatigue crack propagation; Vacuum; Inert gas; Gigacycle fatigue; Internal fracture

\section{Introduction}

An $(\alpha+\beta)$ titanium alloy Ti-6Al-4V is used in various fields as well as in aerospace applications due to its excellent mechanical properties. Especially, its good fatigue property allows its use for the component subjected to severe cyclic loading. The fatigue properties of this alloy were extensively investigated by Lütjering [1-2] and Ritchie [3-4]. On the other hand, the fatigue behavior in the very high cycle regime ( $>10^{7}$ cycles) has recently become a great topic of interest in this alloy. Many researches on this material have reported fatigue fractures originating from the inside of the material (internal fracture) in the very high cycle regime [4-8], whereas the origin is generally on the surface of the material (surface fracture) in the high or low cycle regime. Internal fractures even occur at a stress level lower than the ordinary fatigue limit, which is defined as the fatigue limit of the surface fracture. This fatigue failure 
peculiarity in the very high cycle regime is a serious problem because the conventional fatigue design based on the fatigue limit or fatigue strength at $10^{7}$ cycles of surface fracture might lead to an inaccurate estimation of long term strength. However, the internal small crack propagation processes have not yet been clarified mainly due to the difficulty of observation.

The internal cracks seem to propagate through a vacuum-like environment that is shut off from the air [9-15]. In other words, the effects of oxidation or gas adsorption on crack propagation could be almost ignored in the internal crack propagation processes. On the basis of this concept, we have conducted uniaxial fatigue tests in various vacuum environments to investigate the effects of vacuum-like environment on internal crack propagation processes $[10,14]$. As a result, remarkably similar fracture surfaces were observed between a surface fracture in vacuum and in an internal fracture, although completely different fracture surfaces were obtained between a surface fracture in vacuum and that in air. Also, Benedetti et al. reported that the fracture surface of the shot peened specimen, which fractured by the internal crack, bore a remarkable resemblance to that of the as-received specimen tested in vacuum [15]. These results indicate that the environment inside the internal cracks is similar to a vacuum and has a crucial effect on internal crack propagation.

We also conducted crack propagation tests on Ti-6Al-4V in ultrahigh vacuum focusing on long cracks and clarified that the crack propagation rate $\mathrm{d} a / \mathrm{d} N$ was significantly lower in vacuum than in air $[13,16]$. This result suggests that the long fatigue lives of internal fractures can be attributed to such low propagation rates of internal cracks due to a vacuum-like environment.

The retarding effect on the crack propagation rate in vacuum (or accelerating effect on that in air) has been reported in the literature on various materials [13, 16-18]. In most works including our previous results, however, the effects were discussed using a CT specimen with a long crack of, for example, several to tens of $\mathrm{mm}$ in length. It is well known that small crack propagation behavior is more sensitive to the effects of environments [19-20]; therefore, small crack propagation behavior must be investigated to fully understand effects of vacuum environment on crack propagation.

On the other hand, the vacuum environment is regarded as a typical inert environment. The major difference between the vacuum environment and the other inert environments, such as inert gas environments, is the amount of gases. Regarding the environment inside an internal crack, there is a possibility that the vacuum pressure (roughly corresponding to the amount of gases) is not that low due to the gaseous substances in the materials. In this context, it is of great interest to investigate the effects of the existence of gases on small crack propagation. The small crack propagation test in an inert gas environment is beneficial to investigate the effects of the existence of gases without chemical interaction between the crack and ambient environment.

In the present study, small crack propagation tests were conducted in air and ultrahigh vacuum to clarify the effects of vacuum environment on crack propagation on the basis that the environment inside the internal crack is vacuum-like. The tests were carried out under constant load amplitude 
( $K$-increasing condition) with hourglass specimens. A small cylinder-shaped defect was created on the specimen surface as a crack starter, and a small surface crack originating from the defect was carefully observed to study small crack propagation. Additionally, by focusing on the possibility that the gases in the material affect the internal crack propagation, the same tests were conducted in argon to simply investigate the effects of the existence of gases.

\section{Experimental procedures}

\subsection{Experimental material}

The experimental material was an $(\alpha+\beta)$ titanium alloy Ti-6Al-4V. The chemical composition of the material is shown in Table 1. The supplied material was a $20 \mathrm{~mm}$ diameter round bar that had been heat treated as follows: solution treatment at $1203 \mathrm{~K}$ for $3.6 \mathrm{ks}$ followed by air cooling and over aging at $978 \mathrm{~K}$ for $7.2 \mathrm{ks}$ followed by air cooling. The $(\alpha+\beta)$ dual-phase microstructure was observed as shown in Fig. 1 . The average grain size of each phase was $10 \mu \mathrm{m}$. The mechanical properties are listed in Table 2, and the tensile strength and the elongation were $943 \mathrm{MPa}$ and $17 \%$, respectively.

The material was lathe-turned into hourglass specimens with a parallel part of $\phi 4.1 \times 6 \mathrm{~mm}$. The specimen surfaces were ground with \#120 to \#2000 grit emery paper and then buff-polished with diamond abrasive. The shape and dimensions of the fatigue specimen after polishing are shown in Fig. 2. The diameter of the parallel part after polishing was $\phi 4.0 \mathrm{~mm}$.

An artificial small defect was created on the center of the parallel part as a crack starter by using an excimer laser. The defect was cylinder-shaped with a $30 \mu \mathrm{m}$ diameter and $30 \mu \mathrm{m}$ depth as shown in Fig. 2. The excimer laser machining enables high processing accuracy with negligible heat effects compared to conventional drill machining or general laser machining with, for example, a $\mathrm{CO}_{2}$ or YAG laser. Fig. 3 shows the magnification view around the defect. Burrs generated on the peripheral edge of the defect by the laser machining were completely removed by buff-polishing. In the present work, all the cracks were successfully initiated from the defect. Stage I and initial part of stage IIa of the crack propagation process are unobservable due to the small defect as explained in Section 4.1. However, the specimens with a small defect shown in Fig. 2 are suitable for the aim of the present work, which is to investigate the effect of environment on near-threshold small fatigue crack propagation.

An elastic-plastic stress analysis was performed on the parallel part by using ANSYS to calculate the stress field around the small defect. The axial stress was calculated under an applied external stress of $700 \mathrm{MPa}$, which was the maximum stress used in the tests. As a result, a local disturbance of the stress field was caused due to the small defect as expected. The axial stress at the cross-section in the middle of the specimen, however, saturated at $700 \mathrm{MPa}$ in a region $45 \mu \mathrm{m}$ away from the center of the defect. Therefore, the observation results over crack length $2 a$ (defined in the following section) of $90 \mu \mathrm{m}$ were mainly discussed to ignore the effect of stress concentration due to the small defect. 


\subsection{Experimental conditions}

Crack propagation tests were carried out under constant load amplitude ( $K$-increasing condition) by using an ultrahigh vacuum uniaxial testing machine [12]. The vacuum chamber of the machine was evacuated by using a dry scroll pump and a turbomolecular pump. The ultimate pressure of the chamber is $4.6 \times 10^{-7} \mathrm{~Pa}$. The testing machine is equipped with a vacuum viewport, and the specimen surface can be observed through the viewport. The tests were carried out under sinusoidal waveform loading at a stress ratio $R$ of 0.1 and a test frequency $f$ of $60 \mathrm{~Hz}$. The maximum stress $\sigma_{\max }$ was constant at $700 \mathrm{MPa}$. The test environments were air, ultrahigh vacuum $\left(2.7 \times 10^{-6}-5.3 \times 10^{-6} \mathrm{~Pa}\right)$, and argon $(1 \mathrm{~atm}$ $=1.0 \times 10^{5} \mathrm{~Pa}$ ) at room temperature. For the fatigue tests in argon, the vacuum chamber was evacuated to $10^{-6} \mathrm{~Pa}$ and then purged with argon until the pressure was $1 \mathrm{~atm}$. Two specimens were used for each environmental condition to confirm the reproducibility of the test results.

The tests were interrupted periodically, and the surface crack behavior was monitored by using a digital microscope (Keyence: VHX-2000). The microscope enables a high spatial resolution of submicron order. During the observation, a tensile load equivalent to $80 \%$ of the maximum loading was applied to open the crack. Fig. 4 shows the definition of the crack length $2 a$. In the present work, the crack length $2 a$ was measured as the distance between each of the two crack tips projected to the plane perpendicular to the loading direction.

Following the fatigue tests, fracture surface observations were carried out by using an SEM (Keyence: VE-9800) to investigate the details of the crack propagation behavior in each environment.

\section{Crack propagation behavior}

\subsection{Relation between crack length and number of cycles}

Regardless of the test environment, all specimens failed with a surface crack originating and propagating from the small defect. The crack initiation was detected at less than 1000 cycles in all specimens. As mentioned in Section 2.1, the observation results over the crack length $2 a$ of $90 \mu \mathrm{m}$ were mainly discussed to ignore the effect of stress concentration due to the small defect in the present work. Here, $N_{90}$ is defined as the number of cycles for the crack length $2 a$ to reach $90 \mu \mathrm{m}$, and the values in each environment are shown in Table 3. The results of the two specimens in each environment are identified by the solid and open symbols in the table: solid and open circles in air, solid and open squares in vacuum, and solid and open triangles in argon. $N_{90}$ consists of the number of cycles to crack initiation and that taken for crack propagation to reach the length of $90 \mu \mathrm{m}$. The number of cycles to crack initiation was so small (less than 1000 cycles) in all the specimens that most of $N_{90}$ was considered to be spent on initial crack propagation. 
As shown in the table, $N_{90}$ in argon and that in air had roughly the same order of magnitude. In contrast, $N_{90}$ in vacuum was approximately ten times larger than that in air. These facts suggest that the crack propagation rate just after crack initiation was much lower in vacuum than in air and argon.

The crack length from $2 a=90 \mu \mathrm{m}$ with respect to the number of cycles in each environment are shown in Fig. 5. The vertical axis and the horizontal axis indicate the crack length $2 a$ and the number of cycles $N$, respectively. The shapes of $2 a-N$ curve for each environment are similar as shown in the figure, and the environment inducing the most rapid crack propagation is air, followed by argon and vacuum. In particular, in vacuum, the crack propagated significantly slowly as indicated by the plateau around $1-3 \times 10^{6}$ cycles.

The number of cycles to failure $N_{\mathrm{f}}$ is listed in Table 4 . The environment providing the smallest $N_{\mathrm{f}}$ is air, followed by argon and vacuum. Considering that the $N_{90}$ in argon and that in air were roughly the same, the difference in the $N_{\mathrm{f}}$ between air and argon is caused by the crack propagation in the relatively long crack regime $(2 a>90 \mu \mathrm{m})$. The $N_{\mathrm{f}}$ in vacuum was significantly improved and was two orders of magnitude larger than that in air. The improvement in the $N_{\mathrm{f}}$ in vacuum compared to that in air can be seen in other literature [10, 14, 21-22].

\subsection{Crack propagation rate}

From the measurement results of crack length $2 a$, the crack propagation rate $\mathrm{d} a / \mathrm{d} N$ was calculated, and the relationships with stress intensity factor range $\Delta K$ were investigated. $\mathrm{d} a / \mathrm{d} N$ is defined as the average crack propagation rate $\Delta a / \Delta N$, which is calculated by dividing the crack propagation length $\Delta a$ by the increment of number of cycles $\Delta N$ between two adjacent measuring points. $\Delta K$ was calculated by using Eq. 1 [23].

$\Delta K=F_{\mathrm{I}} \Delta \sigma \sqrt{a}$

where $F_{\mathrm{I}}$ is a coefficient depending on both the aspect ratio of crack $b / a$ and the ratio of crack depth to specimen radius $b / r$ in Fig. 6 . As a result of fracture surface observation, the crack propagated uniformly in all directions from the small defect. Therefore, $b / a$ is determined as 1 . Table 5 shows the relationships between $F_{\mathrm{I}}$ and $a / r$ at $b / a=1$. The $F_{\mathrm{I}}$ at each crack length was calculated using linear interpolation between two values as shown in Table 5 . In the calculation of $\Delta K$, the presence of the small defect was not taken into account since the crack tip dealt with here was sufficiently apart from the edge of the small defect (crack length $2 a>90 \mu \mathrm{m}$ ) [24].

Fig. 7 shows the relationships between $\mathrm{d} a / \mathrm{d} N$ and $\Delta K$ for all test environments: air (circles), vacuum (squares), and argon (triangles). In the figure, the same symbols as used in Fig. 5 are used. As shown in the figure, the crack propagation rates were different depending on the test environments. In this 
section, the results in each environment are explained one by one to investigate the effect of environment on crack propagation rate. Especially in air and vacuum, the small crack behavior obtained in the present work is compared with that of long crack to investigate the effect of crack length.

\subsubsection{Results in air}

Fig. 8 shows the relationships between $\mathrm{d} a / \mathrm{d} N$ and $\Delta K$ in air. The same symbols as used in Fig. 7, solid and open circles, are used. From the good agreement of the two sets of data, the reproducibility of the results was considered sufficient. The crack propagation rates were mostly larger than $10^{-9} \mathrm{~m} /$ cycle in the entire $\Delta K$ range and increased linearly with increasing $\Delta K$ in the logarithmic scale.

Our previous results for long crack (crosses) are also presented in Fig. 8 to investigate the effect of crack length on crack growth behavior [16]. The long crack tests were performed on the same experiment material under $K$-decreasing condition with a stress ratio of 0.1 . A CT specimen with an $8 \mathrm{~mm}$ pre-crack was used for the test. The threshold stress intensity factor range $\Delta K_{\text {th }}$ for the long crack was 4.0 $\mathrm{MPa} \vee \mathrm{m}$. In the present small crack propagation test, the initial stress intensity factor range $\Delta K_{\mathrm{ini}}$ corresponding to $2 a=90 \mu \mathrm{m}$ was about $5 \mathrm{MPa} \sqrt{\mathrm{m}}$ and was larger than the $\Delta K_{\text {th }}$ of the long crack. Thus, small crack behavior below the $\Delta K_{\mathrm{th}}$ of the long crack could not be examined.

Comparing the present results with the previous result at a given $\Delta K$, the $\mathrm{d} a / \mathrm{d} N$ of the present tests was larger than that of the previous test in the lower range of $\Delta K$ (lower than $6.5 \mathrm{MPa} \vee \mathrm{m}$ ). On the other hand, the $\mathrm{d} a / \mathrm{d} N$ of the present and previous results agreed well in the higher $\Delta K$ range. The crack length in the present tests was smaller than that in the previous tests at a given $\Delta K$; therefore, it can be said that the $\mathrm{d} a / \mathrm{d} N$ of the small crack is higher than that of the long crack in the lower $\Delta K$ range. This tendency is consistent with the results reported in the literature [25].

\subsubsection{Results in vacuum}

Fig. 9 shows the relationships between $\mathrm{d} a / \mathrm{d} N$ and $\Delta K$ in vacuum. The same symbols as used in Fig. 7, solid and open squares, are used. As shown in the figure, the reproducibility of the results was also confirmed in vacuum.

Our previous long crack propagation test results under $K$-decreasing condition (crosses) are also presented in Fig. 9 [16]. The threshold stress intensity factor range $\Delta K_{\text {th }}$ of the long crack was 7.8 $\mathrm{MPa} \sqrt{\mathrm{m}}$. Small cracks propagated even below $\Delta K_{\mathrm{th}}$ of the long crack (= 7.8 MPa $\left.\sqrt{\mathrm{m}}\right)$. In the range of $\Delta K$ less than $\Delta K_{\mathrm{th}}$, the crack propagation rates of small cracks decreased with increasing $\Delta K$. The minimum propagation rate was $2.3 \times 10^{-12} \mathrm{~m} /$ cycle at $6.6 \mathrm{MPa} \vee \mathrm{m}$. In the range of $\Delta K$ higher than $\Delta K_{\mathrm{th}}$, the crack propagation rates of small and long cracks agreed well.

In the lower $\Delta K$ range, the crack propagation rates were less than $10^{-10} \mathrm{~m} /$ cycle. The minimum 
amount of crack propagation per loading cycle must be larger than the lattice spacing $\left(\approx 10^{-10} \mathrm{~m}\right)$; therefore, it should be noted that the crack propagation rate shown in Fig. 9 indicates the average crack propagation length per cycle during the measuring period of $\Delta N$. The crack propagation rate could be less than $10^{-10} \mathrm{~m} /$ cycle if the crack could not propagate continuously.

\subsubsection{Comparison between results in air and those in vacuum}

The results of the small crack shown in Fig. 8 and 9 are replotted in Fig. 10 to investigate the effects of the vacuum environment on the crack propagation rate. The crack propagation rate in vacuum was significantly lower than that in air. The difference is about one to three orders of magnitude at a given $\Delta K$, and the pronounced effects of the vacuum were shown in the lower $\Delta K$ range corresponding to the small crack length.

Regarding internal fractures in very high cycle fatigue (VHCF), internal cracks are considered to propagate through the vacuum-like environment as mentioned in Chapter 1 . Then, similarly to the effect in vacuum shown in Fig. 10, the environment around the internal crack can have a retarding effect on crack propagation, which leads to significantly improved fatigue lives compared with the surface crack. Therefore, the occurrence of internal fractures at very high cycle regimes is considered to be due to the vacuum-like environment around the crack.

\subsubsection{Results in argon}

Fig. 11 shows the relationships between $\mathrm{d} a / \mathrm{d} N$ and $\Delta K$ in argon. The reproducibility of the results was also confirmed in argon. The crack propagation rates in argon were mostly larger than $10^{-9}$ $\mathrm{m} /$ cycle in the entire $\Delta K$ range as with those in air; however, the $\mathrm{d} a / \mathrm{d} N-\Delta K$ curves were not linear in the logarithmic scale.

The results in air (circles), vacuum (squares), and argon (triangles) were already shown in Fig. 7 in Section 3.2. The crack propagation rate in argon agreed with that in air in the lower $\Delta K$ range $(<8$ $\mathrm{MPa} \sqrt{\mathrm{m}}$ ); however, it became similar to that in vacuum in the higher $\Delta K$ range (> $11 \mathrm{MPa} \sqrt{\mathrm{m}}$ ). The transition region from air to vacuum was seen in the range $8 \mathrm{MPa} \sqrt{\mathrm{m}}$ to $11 \mathrm{MPa} \sqrt{\mathrm{m}}$. As mentioned in Section 3.1, the $N_{90}$ in argon and that in air were roughly the same, but the $N_{\mathrm{f}}$ were different. This is due to the difference in $\mathrm{d} a / \mathrm{d} N$ in the higher $\Delta K$ range.

Petit et al. reported similar results for aluminum alloy 7075-T651 [26]. They conducted $K$-increasing crack propagation tests with a stress ratio of 0.1 at a frequency of $35 \mathrm{~Hz}$. The test environments were air, vacuum, and nitrogen. In their results, the crack propagation rate in nitrogen was similar to that in air in the lower $\Delta K$ range and to that in vacuum in the higher $\Delta K$ range. This trend of the crack propagation rate in nitrogen is similar to that of Fig. 7. Therefore, our result that $\mathrm{d} a / \mathrm{d} N$ in argon 
agreed with that in air in the lower $\Delta K$ range and with that in vacuum in the higher $\Delta K$ range is not a coincidence; it is an essential effect of the inert gas on the crack propagation process.

\section{Fracture surface observation}

\subsection{Classification of fatigue crack propagation process}

Fig. 12 shows a schematic of the fracture surface of the specimen with the small defect used in the present work. The fatigue crack propagation process is usually classified into three stages according to the crack propagation behavior [27-29]: stage I, stage II, and stage III. Furthermore, stage II can be subdivided into IIa, IIb, and IIc. In the present work, however, stage I and the initial part of stage IIa did not exist because of the small defect. Therefore, the observation of the crack propagation started from the middle of stage IIa.

Fig. 13 (a), (b), and (c) show the SEM image of the fracture surface in air, in vacuum, and in argon, respectively. The magnified view of the fracture surface near the crack initiation site $(\Delta K=7$ $\mathrm{MPa} \sqrt{\mathrm{m}}$ ) in air, in vacuum and in argon are shown in Fig. 14 (a), (b) and (c), respectively. A very rough appearance, typically observed in stage IIa region was observed. The magnified view of the fracture surface far from the crack initiation site $(\Delta K=18 \mathrm{MPa} \sqrt{ } \mathrm{m})$ in air, in vacuum and in argon are shown in Fig. 15 (a), (b) and (c), respectively. A smooth and flat appearance corresponding to stage IIb was observed in this region. In the following discussion, firstly we focus on the transition from stage IIa to stage IIb in each environment. The effect of environment on the fracture surface on stage IIa and stage IIb are discussed in detail in Section 4.2.

The fracture surface appearances were totally different between stage IIa and stage IIb in the high magnification observation as shown in Fig. 14 and 15. Therefore, the two crack propagation stages were distinguished by means of the difference in the appearance on the high magnified views. The dashed semi circles on Fig.13 indicate the boundary between stage IIa and IIb. The transition stress intensity factor range $\Delta K_{\text {trans }}$ at this boundary is shown in Fig. 16. The $\Delta K_{\text {trans }}$ were different depending on the test environment, and the average values of $\Delta K_{\text {trans }}$ in air, in vacuum, and in argon were $11.3 \mathrm{MPa} \sqrt{\mathrm{m}}, 9.1$ $\mathrm{MPa} \sqrt{\mathrm{m}}$, and $10.3 \mathrm{MPa} \sqrt{\mathrm{m}}$, respectively.

Beevers reported that the transition from stage IIa to IIb occurs when the cyclic plastic zone size ahead of crack tip $r_{\mathrm{p}}$ becomes roughly comparable to the grain size of the material [30]. The typical $r_{\mathrm{p}}$ under plane strain condition is given in Eq. 2.

$r_{\mathrm{p}}=\frac{1}{3 \pi}\left(\frac{\Delta K}{2 \sigma_{\mathrm{ys}}}\right)^{2}$

where $\sigma_{\mathrm{ys}}$ is the yield stress. Following Beevers' result, the transition can occur when $r_{\mathrm{p}}$ reached a critical 
size defined by the grain size. However, $\Delta K_{\text {trans }}$ in each environment was apparently different, although these values were obtained from the same sample material (the same grain size). This result indicates that the local yield stress around the crack tip that corresponds to $\sigma_{\mathrm{ys}}$ in Eq. 2 is sensitively affected by the test environments. From Eq. 2, the smaller $\Delta K_{\text {trans }}$ means that there is lower yield stress or higher plasticity around the crack tip. According to Fig. 16, therefore, the plasticity of the material at the crack tip is considered to be greater in vacuum. The high plasticity at the crack tip in vacuum can also be seen in other literature [21, 31-32]. Besides, the difference in $\Delta K_{\text {trans }}$ between argon and vacuum implies that the existence of gases can affect the plasticity of the material, even though they are chemically inert. The difference in plasticity is likely caused by gas adsorption on a newly formed surface at the crack tip. The effects of gas adsorption are discussed more in detail later.

\subsection{Effects of environment on fracture surface}

As shown in Fig. 14, regardless of the test environment, the crystallographic very rough fracture surfaces were recognized in the stage IIa region. Angular features with sharp edges were observed both in the fracture surface in air and in argon. In contrast, the fracture surface in vacuum had more rounded edges and a granular appearance. The fracture surface in argon was therefore different from that in vacuum, but it was similar to that in air in the small crack regime.

In comparison with the fracture surface in stage IIa shown in Fig. 14, a smoother appearance was observed in stage IIb, as shown in Fig. 15. The differences in fracture surface between the environments were less in stage IIb. However, the detailed features were different in terms of the striation pattern. As shown in Fig. 15, the striation patterns were obviously formed in air, while there were no obvious striation patterns in vacuum and in argon.

As above, the fracture surface appearance in argon was quite similar to that in air in the lower $\Delta K$ range. On the other hand, the similarity between the fracture surface in argon and that in vacuum was obtained in the higher $\Delta K$ range. These tendencies are coincident with the trend in the crack propagation rate. As shown in Fig. 7, the crack propagation rate in argon was similar to that in air in the lower $\Delta K$ range and was almost the same as that in vacuum in the higher $\Delta K$ range. The different trends in the crack propagation rate in argon between the higher and lower $\Delta K$ ranges apparently reflect the different crack propagation behavior shown by the fracture surface, which indicates that the effects of argon on the crack propagation rate depend on $\Delta K$ or the crack length.

\section{Discussion}

\subsection{Effects of vacuum on crack propagation}

As mentioned in Section 3.2.3, the crack propagation rate in vacuum was significantly lower 
than that in air (Fig. 10). In this section, the reason for the difference in crack propagation rate between air and vacuum is discussed to figure out the effects of vacuum on crack propagation.

In the literature, the retarding effect of vacuum on various materials including an $(\alpha+\beta)$ titanium alloy has been reported. The literature has pointed out that oxidization or chemical adsorption on a newly-formed slip stage dominantly affects crack propagation in air [19]: a newly-formed slip stage at the crack tip in air is oxidized or chemisorbed in a very short time, while these phenomena hardly ever occur in vacuum. Oxides and adsorbates decrease the surface energy on a newly-formed surface; therefore, the crack can easily propagate in air compared to in vacuum. Namely, the decrease in surface energy in air can explain the relative retarding effect in vacuum.

Oxides and adsorbates on a newly-formed slip stage can also act as obstacles for dislocation motion at the crack tip. Since these phenomena are almost negligible in vacuum, the plastic deformation at the crack tip is easier in vacuum as mentioned in Section 4.1. The high plasticity in vacuum can promote crack tip opening. According to linear fracture mechanics, the large crack tip opening results in a high crack propagation rate. However, plastic strain in vacuum tends to be highly homogenized, and this promotes more blunting of the crack tip than expected by linear fracture mechanics [18]. Additionally, the high plasticity in vacuum causes severe crack closure [21]. The high homogeneity of plastic strain, large blunting of the crack tip, and severe crack closure are considered to be the reasons for the retarding effect of vacuum.

Another important factor affecting the crack propagation rate is reversibility of slip [33-35]. The dislocations moving forward during the loading part of the cycle can reverse during the following unloading part. The reversibility of slip in vacuum is considered to be high due to the absence of oxides and adsorbates, which act as obstacles to reverse slip [33-34]. Pelloux et al. reported that the striation pattern was not observed in vacuum due to the high reversibility of slip [33]. Also, in our present work, the striation pattern was not observed in vacuum, while it was clearly observed in air as mentioned in Section 4.2 (Fig. 15). This fact indicates that the reversibility of slip was higher in vacuum than in air. The high reversibility of slip decreases the real increment of crack propagation in a whole cycle and results in a low crack propagation rate in vacuum.

\subsection{Effects of inert gas on crack propagation}

As discussed in Section 5.1, the difference in crack propagation rate between air and vacuum is explained by mainly chemical interaction such as oxidization or chemical adsorption. In this section, the crack propagation behavior in argon is discussed to understand the effect of a chemically inert environment on crack propagation in detail.

As shown in Section 3.2.4, the crack propagation rate in argon agreed with that in vacuum in the higher $\Delta K$ range. Besides, a striation pattern was not observed in argon in this higher $\Delta K$ range as was 
obtained in vacuum as shown in Fig. 15. These results indicate that the effect of vacuum on crack propagation is almost the same as that in argon in the higher $\Delta K$ range. The common feature of these environments is they are chemically inert; therefore, the effect of vacuum on crack propagation in the higher $\Delta K$ range corresponding to the long crack can be explained by the absence of chemical interaction between the ambient environment and crack.

In the lower $\Delta K$ range, on the other hand, the crack propagation rate in argon was significantly higher than that in vacuum but was the same as that in air, indicating that the effects of vacuum on crack propagation in the lower $\Delta K$ range corresponding to the small crack cannot be explained by only chemical inactivity. The existence of a high amount of argon gas had an accelerating effect on small crack propagation, even though it is chemically inert. Therefore, physical adsorptions on a newly-formed slip stage can be a plausible process to affect the crack propagation rate in argon. The physical adsorption between argon gases and the specimen surface is driven by van der Waals force and charge transfer force [36-37]. Here, charge transfer force is due to the charge transfer from an argon gas to the specimen surface. The physisorbed argon is likely to act in a similar manner to chemisorbates in air, which results in a high crack propagation rate. In other words, the adsorption modes (chemical or physical) have little or no effect on the degree of accelerating effect on small crack propagation.

In the present work, the acceleration effect of argon on the crack propagation rate could be seen only in the small crack regime. Here, several researchers reported that small crack propagation is remarkably sensitive to microstructure [27, 38]. Therefore, the argon gas environment is considered to have a pronounced effect on the microstructure-sensitive crack propagation in the small crack regime.

The effects of inert gas on crack propagation are not yet clear; however, the existence of ambient gases plays an important role in the small crack regime, even though they are chemically inert. The retarding effect of ultrahigh vacuum on crack propagation in the present work is due to the quite low amount of gases, which leads to the absence of both chemical and physical adsorption regardless of crack length. In contrast, the acceleration effect of argon on crack propagation was only seen in the small crack regime. Therefore, there is a possibility that different amounts of gases affect the crack propagation process differently, especially in the small crack regime. Regarding the internal fracture in VHCF, the environment and vacuum pressure inside an internal crack is probably determined by gas content in metals. Therefore, it is very interesting to clarify the effects of vacuum pressure (which roughly correspond to the amount of gases) on fatigue properties. In particular, it is important to investigate the small internal crack propagation in terms of fatigue life prediction since the small crack propagation process accounts for the majority of fatigue lives in VHCF. In this context, the small crack propagation test at various vacuum pressures is necessary to fully understand the internal crack propagation process.

\section{Conclusion}


The underlying idea in the present work is that the internal fatigue crack in the VHCF regime propagates through a vacuum-like environment. To consider the factors affecting this kind of vacuum environment more precisely, small crack propagation tests were carried out on Ti-6Al-4V in air, ultrahigh vacuum, and argon. The fracture surface observation was then conducted to investigate the crack propagation behavior in each environment in more detail. From the results, the effect of the vacuum environment on crack propagation was discussed in terms of the chemical reactivity and the amount of gases. The major results obtained are as follows:

1. The crack propagation rate in vacuum was smaller than that in air. The pronounced effect of vacuum was shown in the small crack regime, and the crack propagation rates were less than $10^{-10} \mathrm{~m} /$ cycle in this regime.

2. As a result of fracture surface observation, the crack propagation behavior in vacuum transferred from stage IIa to IIb at the lower $\Delta K$ range compared with in air. This low transition stress intensity factor range $\Delta K_{\text {trans }}$ in vacuum indicates the high plasticity at the crack tip.

3. Fracture surface observation also revealed that a striation pattern was not found in vacuum but obviously was observed in air. The absence of a striation pattern indicates the high reversibility of slip at the crack tip in vacuum.

4. The retarding effect of vacuum compared with air is explained by the high plasticity and high reversibility of slip. These peculiarities in vacuum are attributed to the absence of oxides and adsorbates on a newly-formed slip stage at the crack tip, which prevent dislocation motion.

5. The crack propagation rate in argon agreed with that in vacuum and was lower than that in air in the higher $\Delta K$ range; however, the crack propagation rate in argon agreed with that in air and was higher than that in vacuum in the lower $\Delta K$ range.

6. Considering that both the vacuum and argon environment are chemically inert, the agreement of the crack propagation rate between argon and vacuum in the higher $\Delta K$ range indicates that chemical interaction such as chemical adsorption plays an important role in this $\Delta K$ range. The crack propagation behavior in vacuum in the higher $\Delta K$ range is therefore mainly explained by the chemical inactivity of the ambient environment.

7. In contrast, the disagreement of the crack propagation rate between argon and vacuum in the lower $\Delta K$ range indicates that the existence of a high amount of ambient gases has a significant effect in the small crack regime, even though they are chemically inert. A plausible process to affect the crack propagation rate in argon is physical adsorption on a newly-formed slip stage at the crack tip. The small crack propagation behavior in vacuum is therefore explained by the quite low amount of gases, resulting in the absence of both chemical and physical adsorption.

\section{Acknowledgement}


The authors acknowledge the support of a Grant-in-Aid for Scientific Research (A, 2012, 24246024) from JSPS.

\section{References}

[1] Lütjering G. Influence of processing on microstructure and mechanical properties of $(\alpha+\beta)$ titanium alloys. Mater Sci Eng A 1998;243;32-45

[2] Hines JA, and Lütjering G. Propagation of microcracks at stress amplitudes below the conventional fatigue limit in Ti-6Al-4V. Fatigue Fract Eng M 1999;22; 657-65

[3] Ritchie RO, Davidson DL, Boyce BL, Campbell JP, and Roder O. High-cycle fatigue of Ti-6Al-4V. Fatigue Fract Eng M 1999;22;621-32

[4] Nalla RK., Boyce BL, Campbell JP, Peters JO, and Ritchie RO. Influence of microstructure on high-cycle fatigue of Ti-6Al-4V: Bimodal vs. lamellar structures. Metall Mater Trans A 2002;33; 899-918

[5] Neal DF, Blenkinsop PA. Internal fatigue origins in $\alpha-\beta$ titanium alloys. Acta Mater 1976;24;59-63

[6] Atrens A, Hoffelner W, Duerig TW, Allison JE. Subsurface crack initiation in high cycle fatigue in Ti-6Al-4V and in a typical stainless steel. Scr Mater 1983;17;601-6

[7] Oguma H, Nakamura T. The effect of microstructure on very high cycle fatigue properties in Ti-6Al-4V. Scr Mater 2010;63;32-4

[8] Sushant KJ, Szczepanski CJ, Golden PJ, Porter III WJ, John R. Characterization of fatigue crack-initiation facets in relation to lifetime variability in Ti-6Al-4V. Int J Fatigue 2012;42;248-57

[9] Nishijima S, Kanazawa K. Stepwise S-N curve and fish-eye failure in gigacycle fatigue. Fatigue Fract Eng M 1999;22;601-7

[10] Nakamura T, Oguma H, Shiina T. Influential factors on interior-originating fatigue fractures of Ti-6Al-4V in gigacycle region: focusing on stress ratio and internal environment of material. In: Lüetjering G, Albrecht J, editors. Ti-2003 Science and Technology, Wheinheim: Wiley-VCH;2004;1775-82

[11] Sakai T. Review and prospects for current studies on very high cycle fatigue of metallic materials for machine structural use. J Solid Mech Mater Eng. 2009;3;425-39

[12] Nakamura T, Oguma H, Shinohara Y. The effect of vacuum-like environment inside sub-surface fatigue crack on the formation of ODA fracture surface in high strength steel. Procedia Eng 2010;2;2121-9

[13] Oguma H, Nakamura T. Fatigue crack propagation properties of Ti-6Al-4V in ultra high vacuum environment. Proceedings of the 18th European Conference of Fracture (ECF18) 2010;ECF18;CD-ROM

[14] Nakamura T, Oguma H. Vacuum fatigue tests of high strength steel to simulate sub-surface fractures. 
In: Berger C, Christ HJ, editors. Fifth International conference on very high cycle fatigue, Berlin: DVM;2011;251-6

[15] Benedetti M, Fontanari V, Bandini M, and Savio E. High-and very high-cycle plain fatigue resistance of shot peened high-strength aluminum alloys: The role of surface morphology. Int $\mathrm{J}$ Fatigue 2015;70; 451-62

[16] Oguma H, Nakamura T. Fatigue crack propagation properties of Ti-6Al-4V in vacuum environments. Int J Fatigue 2013;50;89-93

[17] Grinberg NM. The effect of vacuum on fatigue crack growth. Int J Fatigue 1982;4;83-95

[18] McEvily AJ, Gonzalez Velazquez JL. Fatigue crack tip deformation processes as influenced by the environment. Metall Trans A 1992;23;2211-21

[19] Duquette DJ, Gell M. The effect of environment on the mechanism of Stage I fatigue fracture. Metallurg Trans 1971;2;1325-31

[20] Suresh S, Zamiski GF, Ritchie RO. Oxide-induced crack closure: an explanation for near-threshold corrosion fatigue crack growth behavior. Metallurg Trans A 1981; 12;1435-43

[21] Sugano M, Kanno S, Satake T. Fatigue behavior of titanium in vacuum. Acta Metall 1989;37;1811-20

[22] Shen H, Podlaseck SE, Kramer IR. Effect of vacuum on the fatigue life of aluminum. Acta Metall 1966;14;341-6

[23] Nishitani H, Chen D. Stress intensity factor for a semi-elliptic surface crack in a shaft under tension. Trans JSME A 1984;50;1077-82 (in Japanese)

[24] Murakami Y. Metal Fatigue: Effects of Small Defects and Nonmetallic Inclusions. Elsevier;2002;11-24

[25] Suresh S, Ritchie RO. Propagation of short fatigue cracks. Int Mater rev 1984;29;445-75

[26] Petit J, Zeghloul A. On the effect of environment on short fatigue crack growth behavior and threshold. In: Miller KJ, de los Rios ER, editors. The behavior of short fatigue cracks, London: MEP;1986;163-77

[27] Forsyth PJE. Fatigue damage and crack growth in aluminum alloys. Acta Metall 1963;11;703-15

[28] Birkbeck G, Inckle AE, Waldron WJ. Aspects of Stage II fatigue crack propagation in low-carbon steel. J Mater Sci 1971;6;319-23

[29] Totten G. Fatigue crack propagation. Adv Mater Processes 2008;166;39-41

[30] Beevers CJ. Fatigue crack growth characteristics at low stress intensities of metal and alloys. Met Sci 1977;11;362-7

[31] Ohta A, Sasaki E. Plastic zone around fatigue cracks of pure iron in vacuum and dry air. Acta Metall 1972;20;657-60

[32] Serdyuk VA, Grinberg NM. The plastic zone and growth of fatigue cracks in magnesium MA12 alloy at room and low temperatures. Int J Fatigue 1983;5;79-85

[33] Pelloux RMN. Mechanism of formation of ductile fatigue striations. Trans Am Soc Met 1969;62;281-5

[34] Sriram TS, Ke C-M, Chung YW. Fatigue deformation of silver single crystals: STM evidence for crack nucleation, measurements of slip irreversibility and verification of a new scaling relationship for fatigue life. Acta Metall Mater 1993;41;2515-21

[35] Shyam A, Milligan WW. A model for slip irreversibility, and its effect on the fatigue crack propagation threshold in a nickel-base superalloy. Acta Mater 2005;53;835-44

[36] Küppers J, Nitschké F, Wandelt K, and Ertl G. The adsorption of Xe on Pd (110). Surf Sci 1979;87;295-314 
[37] Ishi S, and Viswanathan B. Adsorption of xenon atoms on metal surfaces. Thin Solid Films 1991;201;373-402

[38] Petit J, Kosche K. Stage I and Stage II propagation of short and long cracks in Ai-Zn-Mg alloys. In. Miller KJ, de los Rios ER, editors. Short fatigue cracks (ESIS 13), London: MEP;1992;135-51 


\section{Figure captions}

Fig. $1(\alpha+\beta)$ dual-phase microstructure of Ti-6Al-4V.

Fig. 2 Shape and dimensions of fatigue specimen after polishing and artificial small defect.

Fig. 3 Surface morphology around artificial small defect.

Fig. 4 Measurement of crack length $2 a$.

Fig. 5 Measurement results of crack length $2 a$ in respect of number of cycles $N$.

Fig. 6 Schematic of crack shape.

Fig. 7 Effects of argon environment on crack propagation rate $\mathrm{d} a / \mathrm{d} N$.

Fig. 8 Relationship between crack propagation rate $\mathrm{d} a / \mathrm{d} N$ and stress intensity factor range $\Delta K$ in air.

Fig. 9 Relationship between crack propagation rate $\mathrm{d} a / \mathrm{d} N$ and stress intensity factor range $\Delta K$ in ultrahigh vacuum.

Fig. 10 Effects of vacuum environment on crack propagation rate $\mathrm{d} a / \mathrm{d} N$.

Fig. 11 Relationship between crack propagation rate $\mathrm{d} a / \mathrm{d} N$ and stress intensity factor range $\Delta K$ in argon.

Fig. 12 Schematic of fracture surface of specimen used.

Fig. 13 SEM images of fracture surface.
(a) In air
(b) In ultrahigh vacuum
(c) In argon

Fig. 14 SEM images of fracture surface in stage IIa region $(\Delta K=7 \mathrm{MPa} \sqrt{\mathrm{m}})$.
(a) In air
(b) In ultrahigh vacuum
(c) In argon

Fig. 15 SEM images of fracture surface in stage IIb region $(\Delta K=18 \mathrm{MPa} \sqrt{\mathrm{m}})$.
(a) In air
(b) In ultrahigh vacuum
(c) In argon

Fig. 16 Transition stress intensity factor range between stage IIa and IIb $\Delta K_{\text {trans. }}$

\section{Table captions}

Table 1 Chemical composition of Ti-6Al-4V (mass\%).

Table 2 Mechanical properties of Ti-6Al-4V.

Table 3 Number of cycles for crack length 2a to reach $90 \mu \mathrm{m} N_{90}$.

Table 4 Number of cycles to failure $N_{\mathrm{f}}$.

Table 5 Values of coefficient $F_{\text {I }}$ at $b / a=1$. 


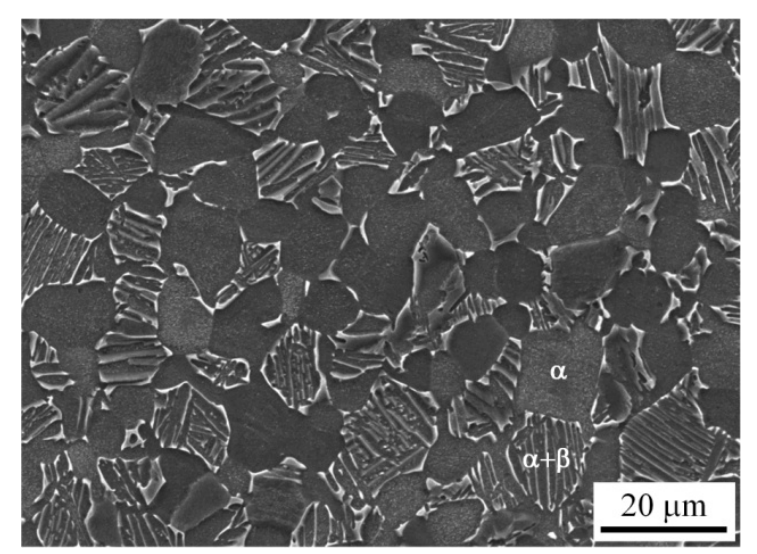

Fig. $1(\alpha+\beta)$ dual-phase microstructure of Ti-6Al-4V.

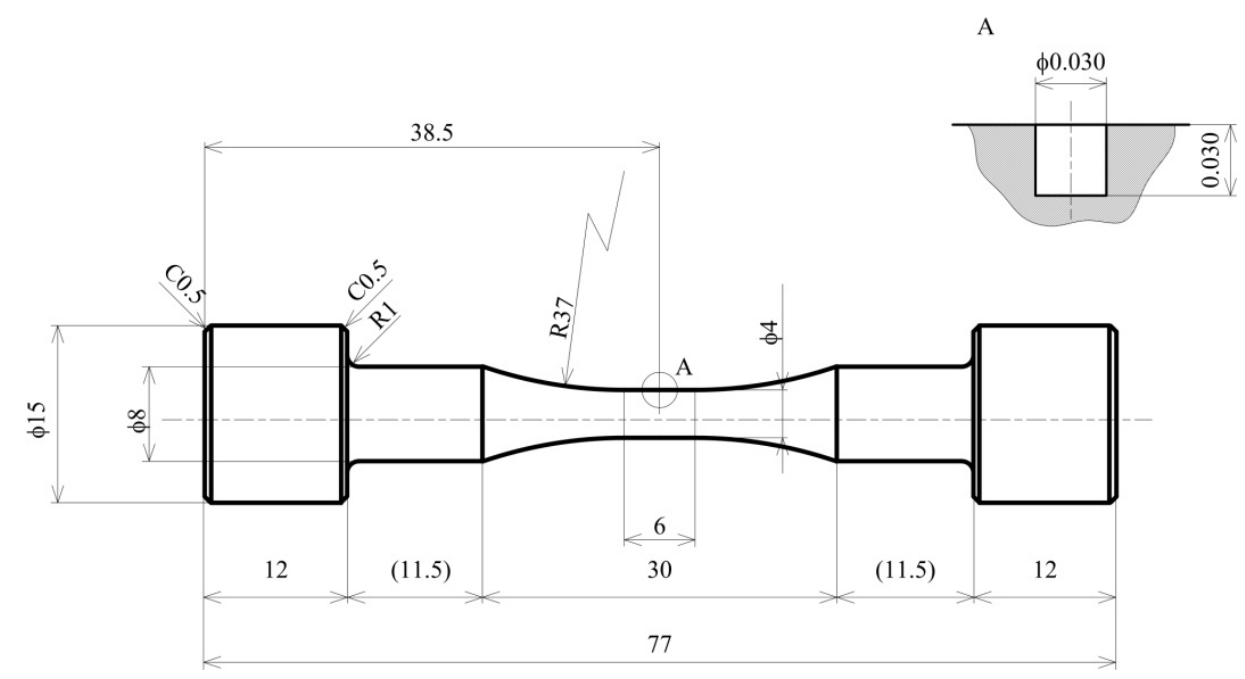

Fig. 2 Shape and dimensions of fatigue specimen after polishing and artificial small defect.

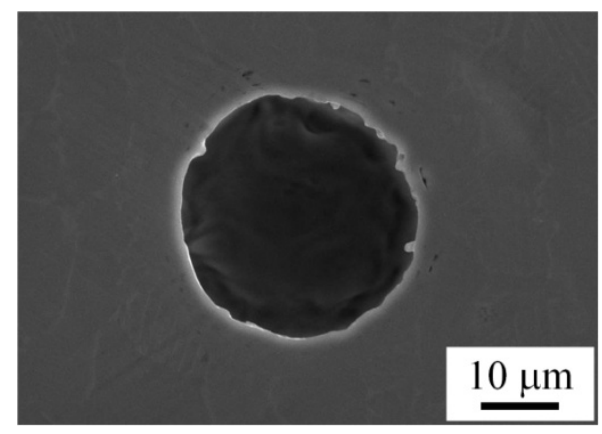

Fig. 3 Surface morphology around artificial small defect. 


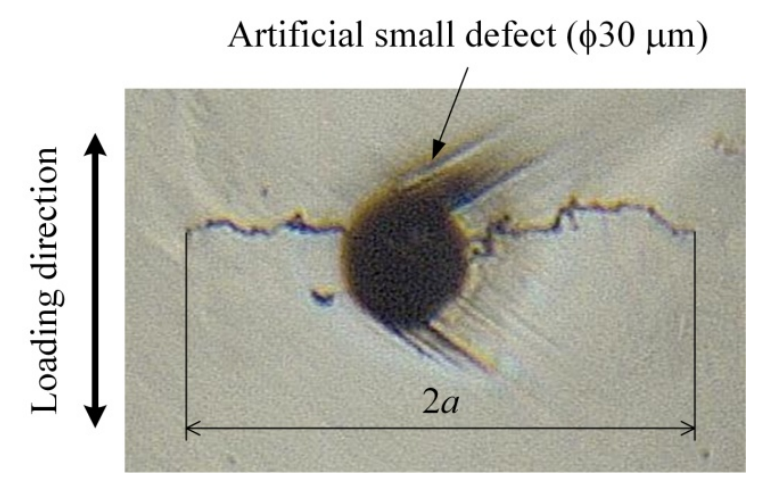

Fig. 4 Measurement of crack length $2 a$.

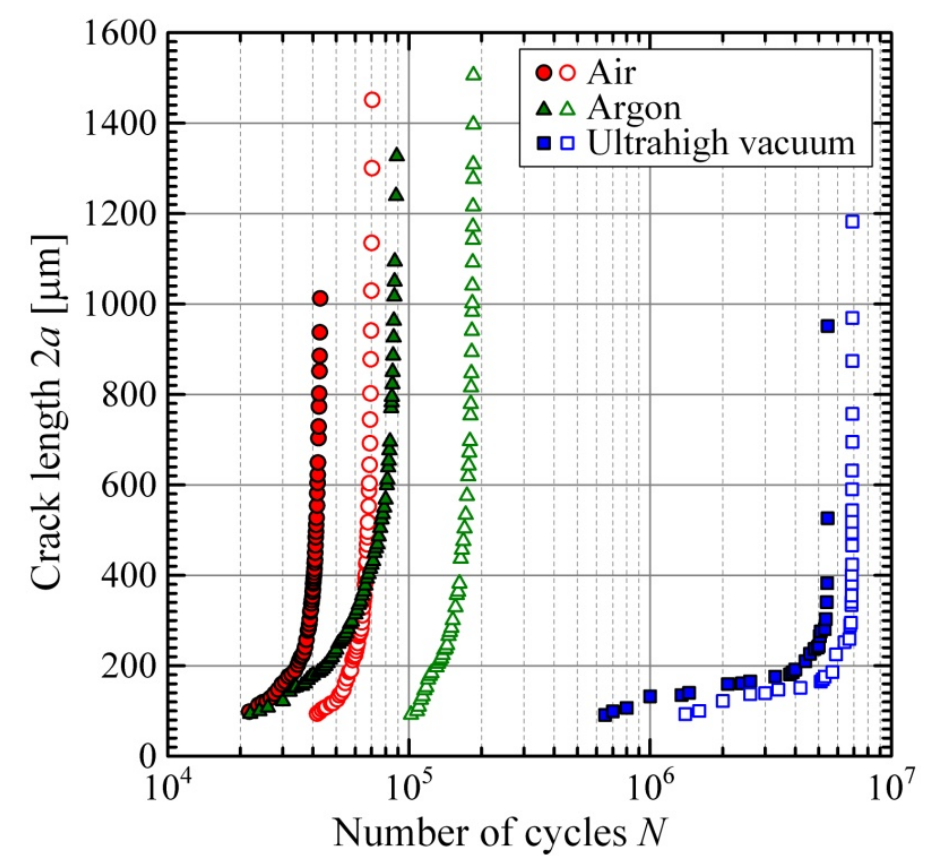

Fig. 5 Measurement results of crack length $2 a$ in respect of number of cycles $N$.
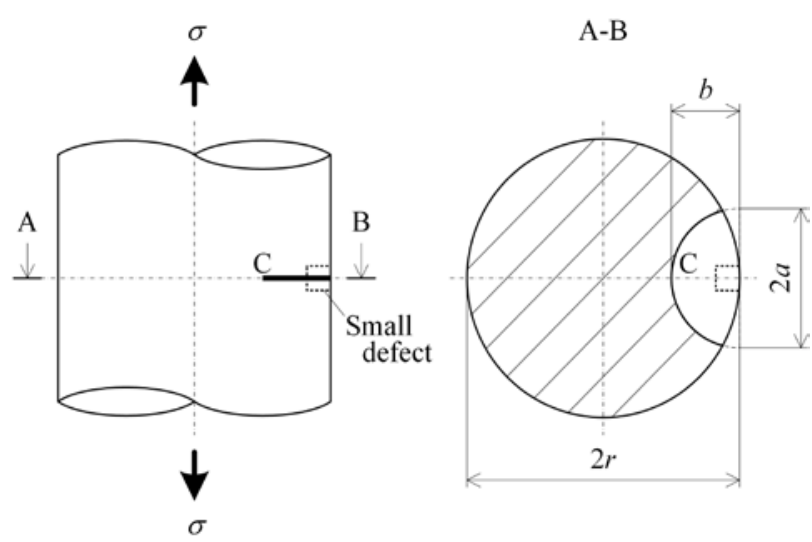

Fig. 6 Schematic of crack shape. 


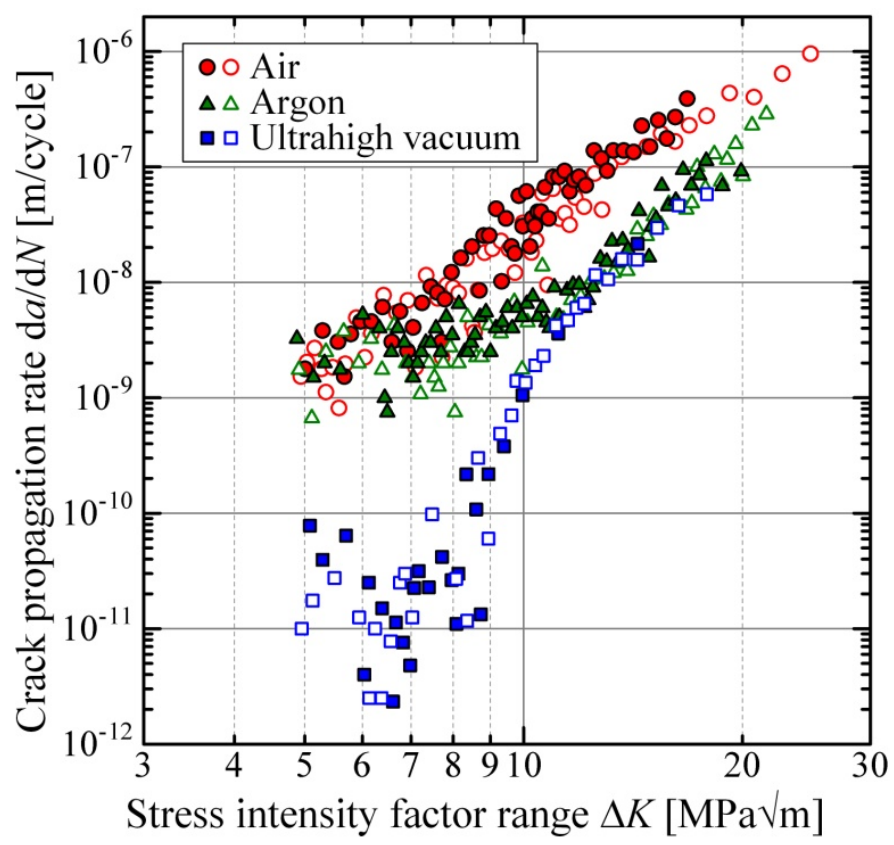

Fig. 7 Effects of argon environment on crack propagation rate $\mathrm{d} a / \mathrm{d} N$.

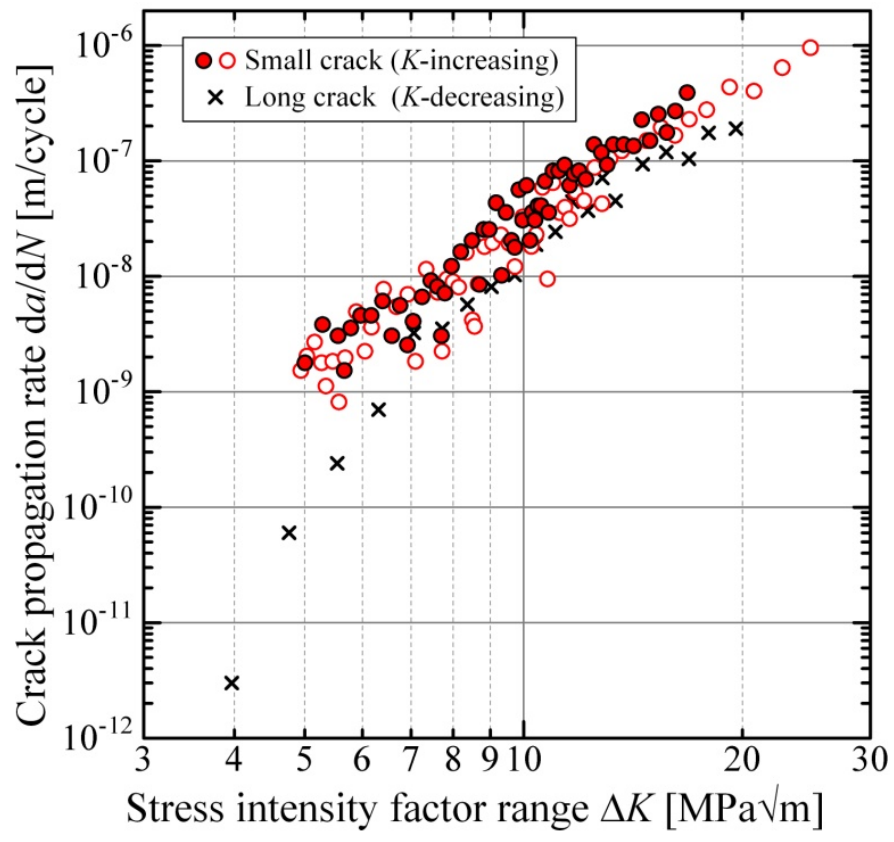

Fig. 8 Relationship between crack propagation rate $\mathrm{d} a / \mathrm{d} N$ and stress intensity factor range $\Delta K$ in air. 


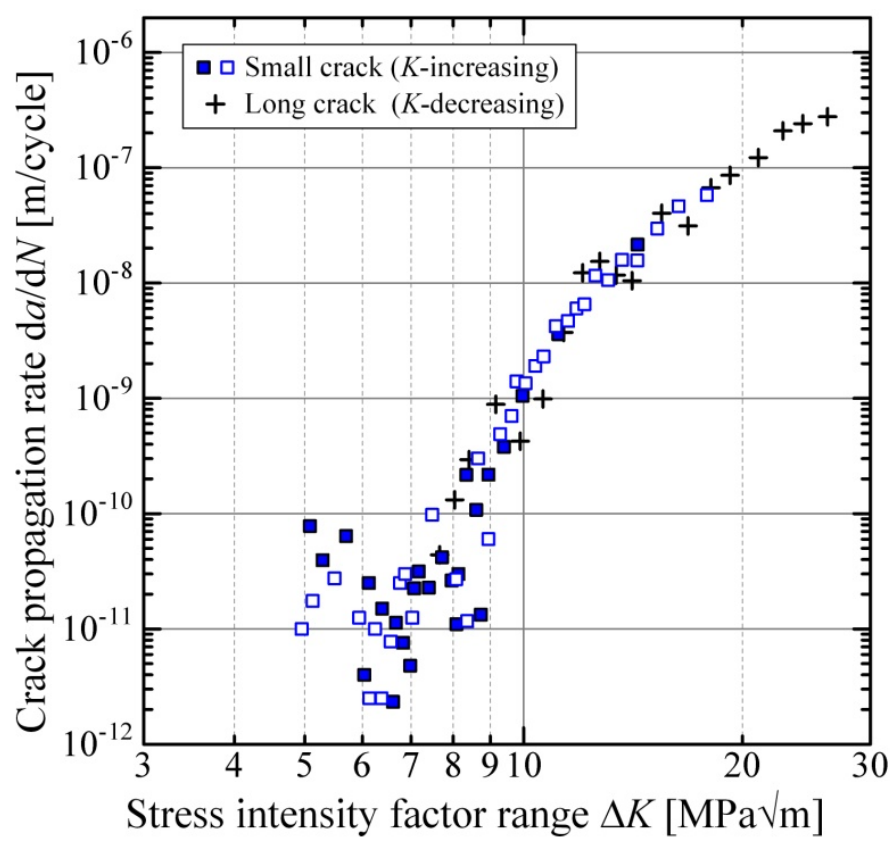

Fig. 9 Relationship between crack propagation rate $\mathrm{d} a / \mathrm{d} N$ and stress intensity factor range $\Delta K$ in ultrahigh vacuum.

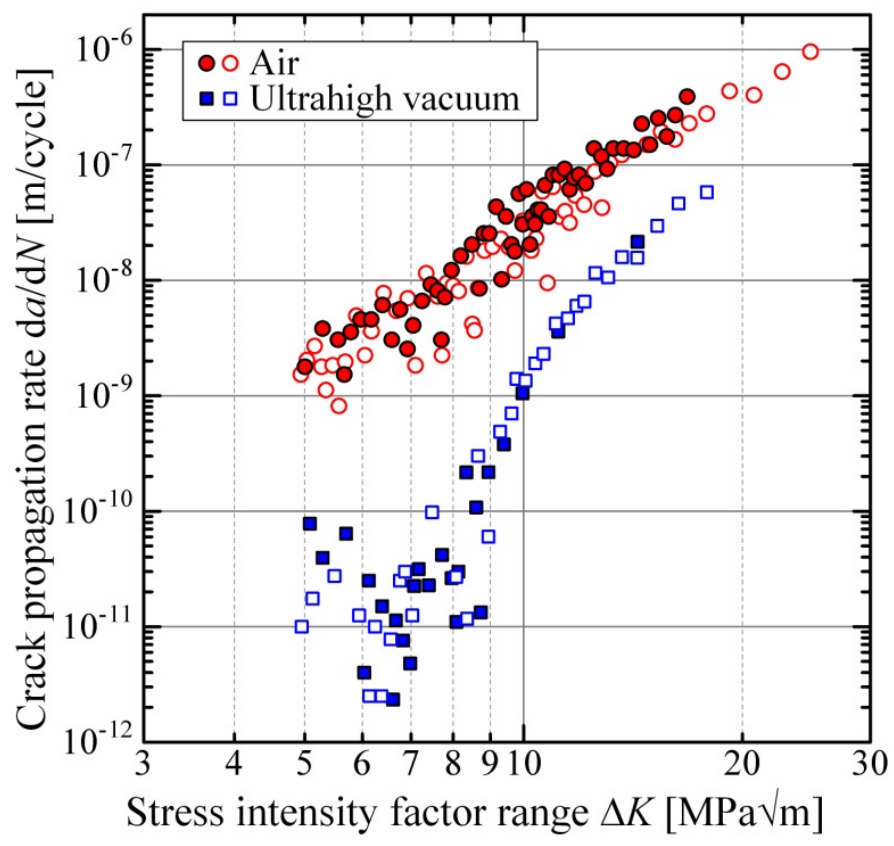

Fig. 10 Effects of vacuum environment on crack propagation rate $\mathrm{d} a / \mathrm{d} N$. 


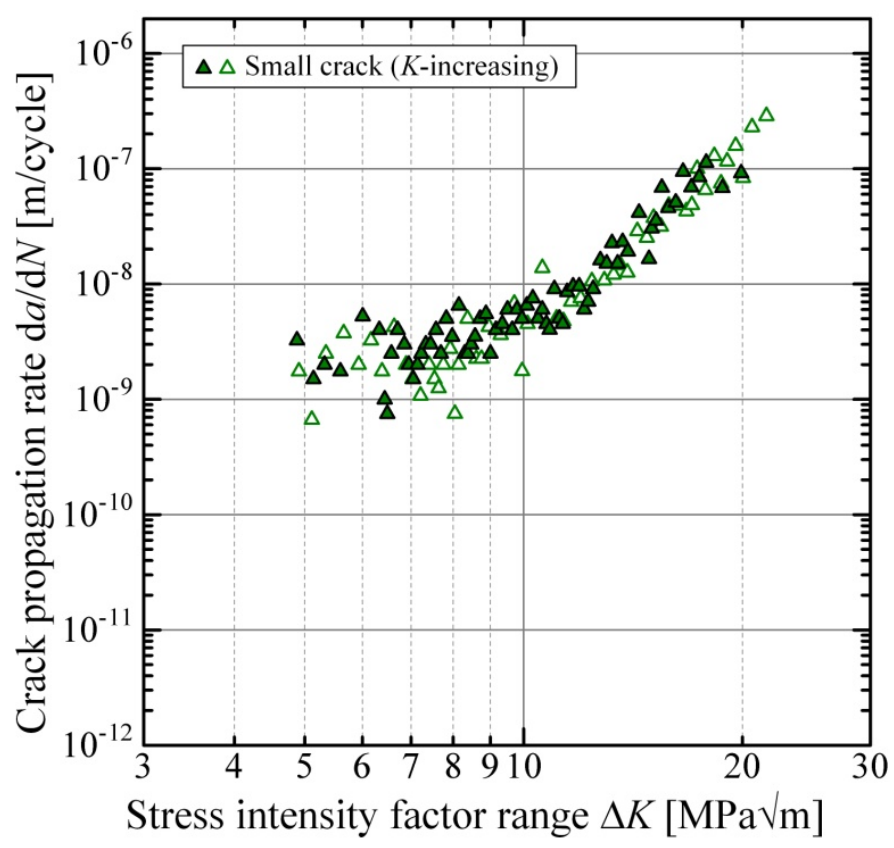

Fig. 11 Relationship between crack propagation rate $\mathrm{d} a / \mathrm{d} N$ and stress intensity factor range $\Delta K$ in argon.

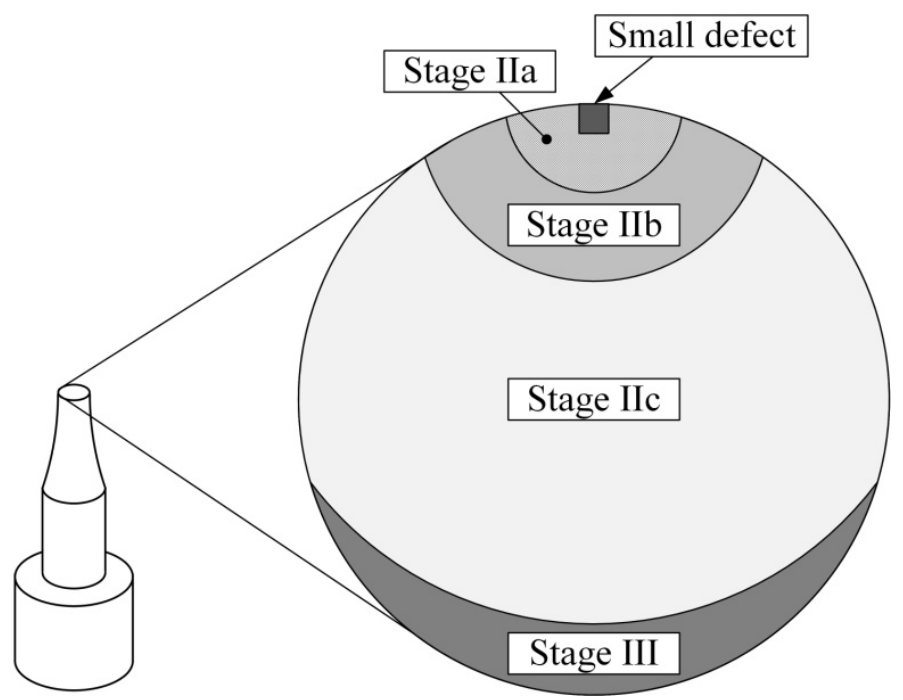

Fig. 12 Schematic of fracture surface of specimen used. 


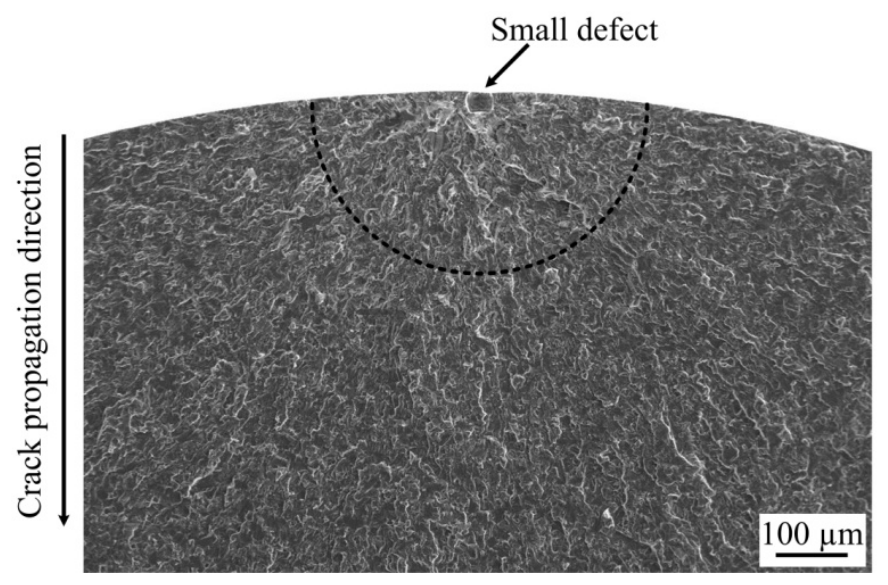

(a) In air

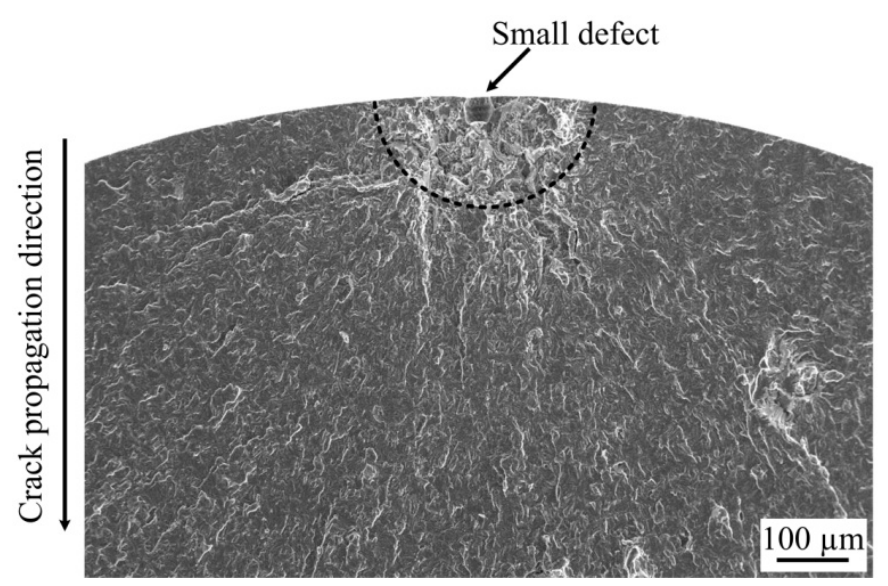

(b) In ultrahigh vacuum

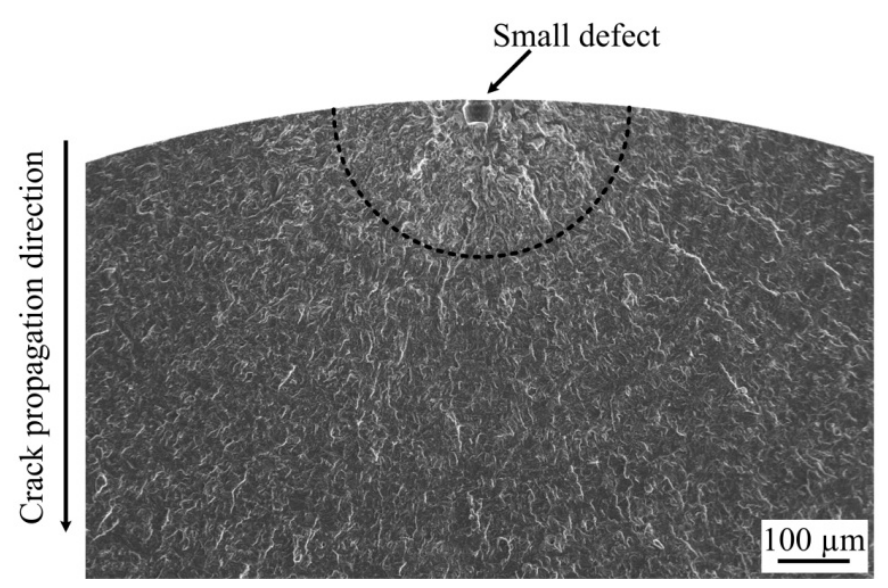

(c) In argon

Fig. 13 SEM images of fracture surface. 


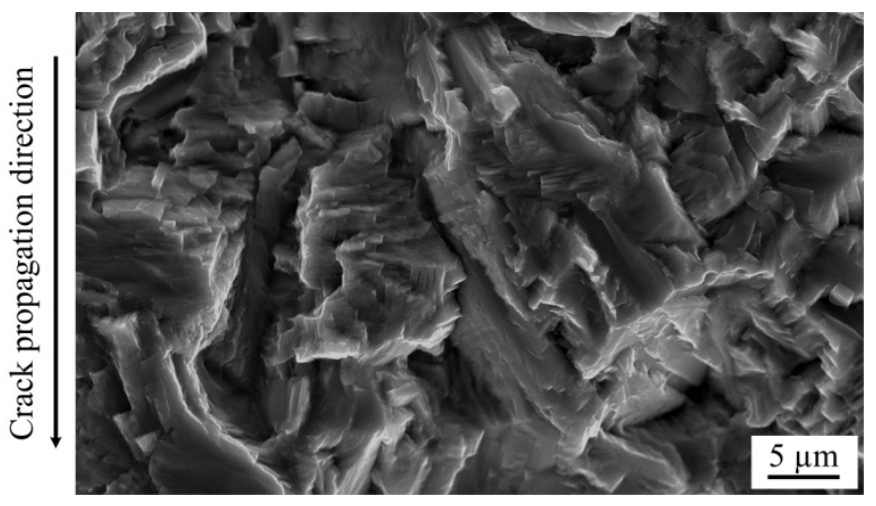

(a) In air

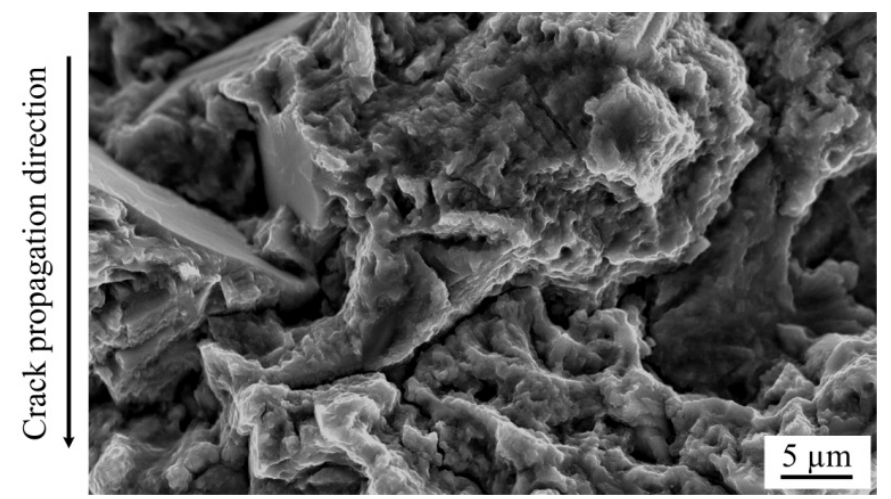

(b) In ultrahigh vacuum

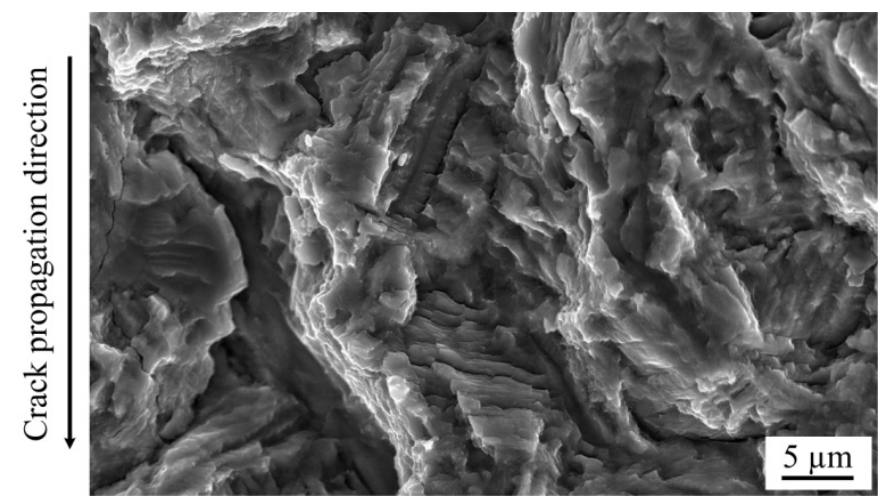

(c) In argon

Fig. 14 SEM images of fracture surface in stage IIa region $(\Delta K=7 \mathrm{MPa} \sqrt{\mathrm{m}})$. 


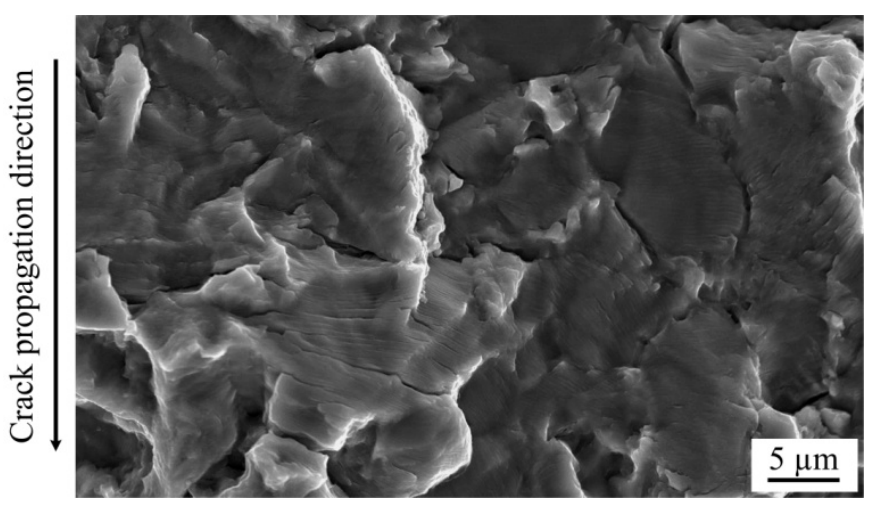

(a) In air

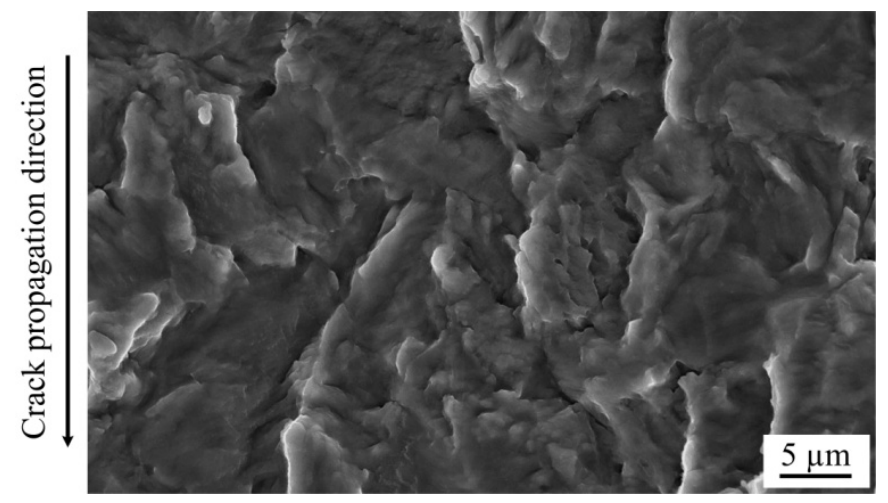

(b) In ultrahigh vacuum

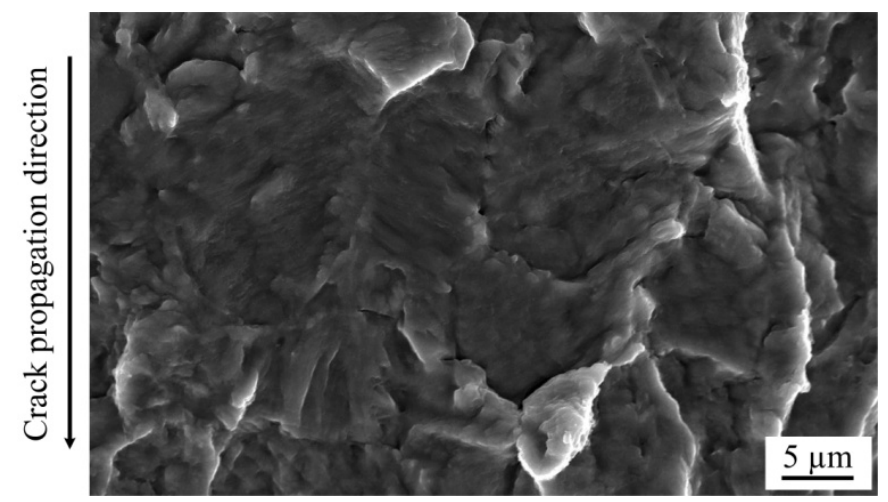

(c) In argon

Fig. 15 SEM images of fracture surface in stage IIb region $(\Delta K=18 \mathrm{MPa} \sqrt{\mathrm{m}})$. 


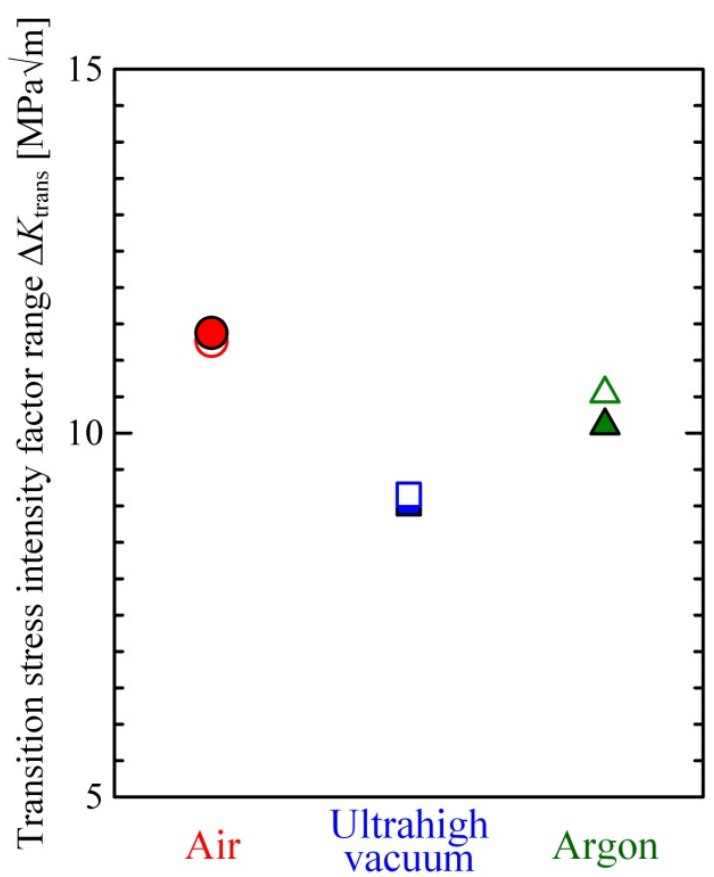

Fig. 16 Transition stress intensity factor range between stage IIa and IIb $\Delta K_{\text {trans }}$. 
Table 1

Chemical composition of Ti-6Al-4V (mass\%).

\begin{tabular}{cccccccc}
\hline $\mathrm{Al}$ & $\mathrm{V}$ & $\mathrm{O}$ & $\mathrm{N}$ & $\mathrm{C}$ & $\mathrm{Fe}$ & $\mathrm{H}$ & $\mathrm{Ti}$ \\
\hline $\mathbf{6 . 1 2}$ & $\mathbf{4 . 2 7}$ & $\mathbf{0 . 1 6}$ & $\mathbf{0 . 0 0 2}$ & $\mathbf{0 . 0 2}$ & $\mathbf{0 . 1 5}$ & $\mathbf{0 . 0 0 2 9}$ & Bal. \\
\hline
\end{tabular}

Table 2

Mechanical properties of Ti-6Al-4V.

\begin{tabular}{ccccc}
\hline $\begin{array}{c}\text { Tensile strength } \\
{[\mathrm{MPa}]}\end{array}$ & $\begin{array}{c}0.2 \% \text { proof stress } \\
{[\mathrm{MPa}]}\end{array}$ & $\begin{array}{c}\text { Elongation } \\
(\%)\end{array}$ & $\begin{array}{c}\text { Reduction of area } \\
(\%)\end{array}$ & $\begin{array}{c}\text { Hardness } \\
(\mathrm{Hv})\end{array}$ \\
\hline $\mathbf{9 4 3}$ & $\mathbf{8 6 0}$ & $\mathbf{1 7}$ & $\mathbf{4 0}$ & $\mathbf{3 1 6}$ \\
\hline
\end{tabular}

Table 3

Number of cycles for crack length $2 a$ to reach $90 \mu \mathrm{m} N_{90}$.

\begin{tabular}{c|c}
\hline \multirow{2}{*}{ In air } & $\bullet 2.2 \times 10^{4}$ \\
\cline { 2 - 2 } & $\circ 4.2 \times 10^{4}$ \\
\hline \multirow{2}{*}{ In ultrahigh vacuum } & $\square 6.5 \times 10^{5}$ \\
\cline { 2 - 2 } & $\square 1.4 \times 10^{6}$ \\
\hline \multirow{2}{*}{ In argon } & $\Delta 2.2 \times 10^{4}$ \\
\cline { 2 - 2 } & $\Delta 1.0 \times 10^{5}$ \\
\hline
\end{tabular}

\section{Table 4}

Number of cycles to failure $N_{\mathrm{f}}$.

\begin{tabular}{c|c}
\hline \multirow{2}{*}{ In air } & $\bullet 4.6 \times 10^{4}$ \\
\cline { 2 - 2 } & $\circ 7.2 \times 10^{4}$ \\
\hline \multirow{3}{*}{ In ultrahigh vacuum } & $\square 5.5 \times 10^{6}$ \\
\cline { 2 - 2 } & $\square 6.9 \times 10^{6}$ \\
\hline \multirow{2}{*}{ In argon } & $\Delta 9.2 \times 10^{4}$ \\
\cline { 2 - 2 } & $\Delta 1.9 \times 10^{5}$ \\
\hline
\end{tabular}

Table 5

Values of coefficient $F_{\mathrm{I}}$ at $b / a=1$.

\begin{tabular}{c|ccccc}
\hline$a / r$ & 0 & 0.125 & 0.250 & 0.375 & 0.500 \\
\hline$F_{I}$ & 0.660 & 0.665 & 0.683 & 0.714 & 0.758 \\
\hline
\end{tabular}

